\title{
Targeting insulin to the liver corrects defects in glucose metabolism caused by peripheral insulin delivery
}

\author{
Dale S. Edgerton, ${ }^{1}$ Melanie Scott, ${ }^{1}$ Ben Farmer, ${ }^{1}$ Phillip E. Williams, ${ }^{2}$ Peter Madsen, ${ }^{3}$ \\ Thomas Kjeldsen, ${ }^{3}$ Christian L. Brand, ${ }^{3}$ Christian Fledelius, ${ }^{3}$ Erica Nishimura, ${ }^{3}$ \\ and Alan D. Cherrington ${ }^{1}$ \\ 'Vanderbilt University School of Medicine, Department of Molecular Physiology and Biophysics, Nashville, Tennessee, \\ USA. ${ }^{2}$ Vanderbilt University Medical Center, Division of Surgical Research, Nashville, Tennessee, USA. ${ }^{3}$ Research and \\ Development, Novo Nordisk A/S, Novo Nordisk Park, Maaleov, Denmark.
}

Peripheral hyperinsulinemia resulting from subcutaneous insulin injection is associated with metabolic defects that include abnormal glucose metabolism. The first aim of this study was to quantify the impairments in liver and muscle glucose metabolism that occur when insulin is delivered via a peripheral vein compared to when it is given through its endogenous secretory route (the hepatic portal vein) in overnight-fasted conscious dogs. The second aim was to determine if peripheral delivery of a hepato-preferential insulin analog could restore the physiologic response to insulin that occurs under meal-feeding conditions. This study is the first to our knowledge to show that hepatic glucose uptake correlates with insulin's direct effects on the liver under hyperinsulinemic-hyperglycemic conditions. In addition, glucose uptake was equally divided between the liver and muscle when insulin was infused into the portal vein, but when it was delivered into a peripheral vein the percentage of glucose taken up by muscle was 4-fold greater than that going to the liver, with liver glucose uptake being less than half of normal. These defects could not be corrected by adjusting the dose of peripheral insulin. On the other hand, hepatic and nonhepatic glucose metabolism could be fully normalized by a hepato-preferential insulin analog.

Conflict of interest: DSE receives speaking fees from Novo Nordisk. PM, TK, CLB, CF, and EN are employees of Novo Nordisk. ADC receives research support, holds a patent (W0/2018/144867) with, serves as consultant for, and holds stock options with Abvance; serves as a consultant for and has submitted a patent with Biocon; serves as a consultant for and holds stock options with Fractyl, Metavention, Sensulin Labs, and Thetis Pharmaceuticals; serves as a consultant for and receives research support from Novo Nordisk; serves on the scientific advisory board of and holds stock options and a patent (number 9,649,293) with Zafgen; and receives research support from Diasome.

Copyright: (c) 2019, American Society for Clinical Investigation.

Submitted: December 20, 2018 Accepted: February 21, 2019 Published: April 4, 2019.

Reference information: /CI Insight. 2019;4(7):e126974. https://doi. org/10.1172/ji.insight.126974.

\section{Introduction}

The liver plays an essential role in maintaining glucose homeostasis. During fasting it is the primary source of circulating glucose, whereas following a meal it becomes a major site of glucose storage. In humans, two-thirds of the day is spent with the liver taking up glucose (1) and the liver is responsible for disposing of as much as a third of ingested glucose, a quantity equaling that disposed of by muscle $(2,3)$. Thus, the liver is critical to maintaining both fasting glycemia and limiting postprandial hyperglycemia. Insulin is normally a key regulator of the liver's transition between fasting and feeding, but this process is impaired in individuals with diabetes $(4,5)$.

Typical insulin treatment is suboptimal because subcutaneous insulin administration generates pharmacokinetics and pharmacodynamics that do not replicate those associated with endogenous release (6). Various alternatives are in development, including hepato-preferential insulin analogs that are intended to mimic the effects of endogenous secretion of insulin $(7,8)$, and oral $(9,10)$ or intraperitoneal $(11,12)$ routes of administration that take advantage of the portal vein route of absorption and therefore more closely replicate endogenous insulin secretion $(9,13)$. Whether or not these treatments will confer a therapeutic advantage depends on the metabolic consequences of activating insulin's direct hepatic versus indirect mechanisms of action as well as how the distribution of insulin determines patterns of glucose uptake across various tissues. Insulin directly suppresses hepatic glucose production (HGP) in response to the binding of the hormone to its liver receptor (14-16), but it can also act indirectly through its effects on nonhepatic tissues (e.g., via the suppression of lipolysis) (17-21). When insulin is administered peripherally its indirect mechanisms of control become more pronounced because the normal 3:1 insulin gradient between the liver and the rest of the body is eliminated $(15,22,23)$. Of note, most studies have investigated hepatic insulin action under euglycemic rather than hyperglycemic conditions even though portal vein glucose 
delivery $(24)$ and hyperglycemia $(25,26)$ each also regulate liver glucose flux. Thus, it is unknown whether hyperglycemia and hyperinsulinemia achieved via portal vein delivery interact to produce outcomes that would not otherwise be present.

It is important to recognize that insulin-stimulated hepatic glucose uptake (HGU) is quantitatively of greater consequence to postprandial glucose metabolism than is the suppression of HGP (increase of $4-5 \mathrm{mg} / \mathrm{kg} / \mathrm{min}$ vs. decrease of $2 \mathrm{mg} / \mathrm{kg} / \mathrm{min}$, respectively) (24). Unfortunately, lack of surgical access to hepatic vasculature in humans and rodents means that HGU cannot be directly measured in those species; therefore, less is known about the mechanisms by which insulin regulates HGU. Thus, the first aim of this study was to compare the effect of the same dose of insulin, administered either via a peripheral vein or the hepatic portal vein, on the suppression of HGP and stimulation of HGU during hyperglycemic postprandial conditions, and to quantify the effect of differences in vascular insulin distribution on glucose storage patterns across tissues. If insulin primarily regulates HGP and HGU through indirect, nonhepatic mechanisms, then peripheral insulin delivery should generate the greatest liver effects, but if insulin predominantly acts via direct mechanisms then suppression of HGP and stimulation of HGU should be greater with intraportal insulin. To account for the fact that glucose uptake may depend not only on insulin concentrations but also on the total load of glucose administered, in a third group insulin was infused peripherally at a variable rate in order to match that group's glucose infusion rate (GIR) to the GIR of the portal vein insulin delivery group. Thus, either the insulin dose or the total mass of glucose administered (i.e., insulin's pharmacodynamic effect) was matched between groups.

Previously, we found that a peripherally delivered acylated insulin model compound (insulin-327) was hepato-preferential with regard to glucose turnover under euglycemic, near-basal insulin conditions (7). The efficacy of such an analog under postprandial conditions has not been tested, however. Therefore, our second aim was to quantify the effect of insulin-327 on the rates and distribution of glucose uptake by the liver and muscle during meal-simulated conditions (hyperinsulinemic, hyperglycemic clamp with portal vein glucose infusion) and thus to determine if, in principle, a peripherally delivered insulin analog could normalize postprandial glucose metabolism. These studies were performed in dogs because of the similarity in insulin-regulated glucose metabolism between humans and canines and because this model permits cannulation of the necessary vessels and measurement of the blood flow that is required for measuring hepatic and nonhepatic glucose uptake.

\section{Results}

At the start of the experimental period regular human insulin was delivered at the same rate $(7.2 \mathrm{pmol} / \mathrm{kg} /$ min; Figure 1A) either into a peripheral vein (PeHI) or the hepatic portal vein (i.e., the endogenous secretory route; PoHI). In a third group insulin was infused peripherally at a variable rate (PeHI-half), adjusted during the study to cause that group's GIR to match that of PoHI. After a brief priming period the steadystate insulin infusion rate required to do this was $3.6 \pm 0.4 \mathrm{pmol} / \mathrm{kg} / \mathrm{min}$ in PeHI-half. Thus, either the insulin dose (PoHI vs. PeHI) or the hormone's pharmacodynamic effect (PoHI vs. PeHI-half) was matched. In another group (Pe327) insulin-327 was infused into a peripheral vein at a variable rate so as to match the GIR seen in PoHI (the steady state insulin-327 rate was $22.1 \pm 1.6 \mathrm{pmol} / \mathrm{kg} / \mathrm{min}$ ).

As expected, the route of insulin delivery determined its distribution in the body. Plasma insulin levels were similar in all groups during the basal period ( -30 to 0 minutes), with hepatic sinusoidal levels being 2- to 3 -fold greater than the arterial level due to endogenous secretion of insulin into the portal vein (Figure 1, B-D). When insulin was infused into the portal vein the arterial and hepatic sinusoidal insulin levels increased to $125 \pm 14$ and $400 \pm 41 \mathrm{pM}$, respectively, during the last 2 hours of the clamp. In contrast, the same rate of insulin infusion into a leg vein resulted in arterial levels that were twice as great $(276 \pm 9 \mathrm{pM})$ and hepatic sinusoidal levels that were half as much $(226 \pm 7 \mathrm{pM})$ as compared with the portal route. In PeHI-half the arterial insulin levels were approximately $20 \%$ greater than in PoHI, while the liver's exposure to insulin was reduced by approximately $75 \%$. Thus, the endogenous 3:1 liver-to-peripheral tissue insulin gradient was maintained during the clamp in PoHI but this gradient was completely eliminated $(<1)$ in PeHI and PeHI-half (Figure 2A). The route of insulin delivery did not affect the fractional extraction of insulin by the liver (Figure $2 \mathrm{~B}$ ); therefore, the reductions in net hepatic insulin uptake (Figure 2C) were attributable to the lower loads of insulin reaching the liver when insulin was delivered peripherally (Figure 2D). In accordance with this, whole-body plasma insulin clearance was reduced by more than half when insulin was infused into a leg vein (Figure 2E). Because insulin-327 clearance is much lower than that of 
regular insulin (7), arterial and hepatic insulin-327 levels were high and not distinguishable between vessels (arterial, portal vein, and hepatic vein insulin-327 levels were 52,314 \pm 7,551; 51,100 \pm 8,146; and 49,157 $\pm 7,464$ pM; respectively, at the end of the study; data not shown). Arterial and hepatic sinusoidal plasma glucagon levels remained basal throughout and did not differ between groups (Figure 3, A and B).

Plasma glucose levels doubled (Figure 4A) in all groups during the experimental period as a result of glucose infusions into the hepatic portal vein $(4 \mathrm{mg} / \mathrm{kg} / \mathrm{min}$ in all groups to stimulate the hepatic feeding signal) and as necessary into a leg vein to clamp at $200 \mathrm{mg} / \mathrm{dl}$. Total GIRs were significantly greater in $\mathrm{PeHI}$ than the other groups over the last 90 minutes of the experiment but by design were similar in PoHI, PeHI-half, and Pe327 (Figure 4B). The glucose requirement was determined by the extent to which insulin suppressed endogenous glucose production (EGP) and increased whole-body glucose uptake. EGP was rapidly and completely suppressed by portal vein insulin delivery (reduced by $50 \%$ at 30 minutes and $100 \%$ at 90 minutes; Figure 4C). In contrast, the same dose of insulin into a leg vein had a delayed effect (EGP was reduced by $50 \%$ at 60 minutes and it took more than 120 minutes for complete suppression to occur). In PeHI-half the suppression of EGP was both delayed and incomplete (only suppressed by $75 \%$ at the end of the experiment) in spite of arterial insulin levels that were initially greater (first hour) and later equal to those in PoHI (Figure 1B). This reinforces the notion that the liver's rapid on-off response to insulin (6) is a reaction to the direct effects of the hormone (16). Thus, under simulated meal conditions the peripheral (indirect) actions of insulin were significantly less effective at regulating EGP than those of portally delivered insulin, even when arterial insulin levels were more than 2-fold higher (Figure 1D). On the other hand, peripheral insulin-327 replicated the effect of portal vein insulin delivery on EGP almost exactly (Figure 4C).

Insulin-dependent whole-body glucose utilization, which is comprised primarily of liver and muscle glucose uptake, increased a great deal in $\mathrm{PeHI}(18.3 \pm 1.1 \mathrm{mg} / \mathrm{kg} / \mathrm{min}$ during the last 2 hours of the study; Figure 4D). On the other hand, in PoHI glucose utilization was significantly lower $(11.0 \pm 0.4 \mathrm{mg} / \mathrm{kg} / \mathrm{min})$ and similar to that in PeHI-half $(12.5 \pm 0.9 \mathrm{mg} / \mathrm{kg} / \mathrm{min})$ and Pe327 (10.4 $\pm 1.1 \mathrm{mg} / \mathrm{kg} / \mathrm{min})$. During the clamp the liver rapidly shifted from net hepatic glucose output during the basal fasting period $(\sim 1.5 \mathrm{mg} / \mathrm{kg} /$ $\mathrm{min}$ ) to uptake, which averaged $5.0 \pm 0.9 \mathrm{mg} / \mathrm{kg} / \mathrm{min}$ during the last 2 hours of the clamp in PoHI (Figure $4 \mathrm{E})$. In comparison, rates of net hepatic glucose uptake (NHGU) in PeHI, PeHI-half, and Pe327 were 3.6 $\pm 0.6,2.8 \pm 0.4$, and $4.0 \pm 0.6 \mathrm{mg} / \mathrm{kg} / \mathrm{min}$, respectively, during that period. The 3 primary regulators of HGU are insulin, the hepatic glucose load, and a negative arterial-to-portal vein glucose gradient (24). The latter 2 did not differ between groups (Figure 4, F and G); instead, it was insulin's effect on net hepatic glucose fractional extraction (Figure $4 \mathrm{H}$ ) that determined NHGU. With regard to muscle, nonhepatic glucose uptake was stimulated minimally by intraportal insulin and insulin-327 but it increased significantly in response to peripheral insulin delivery (Figure 4I). Thus, peripheral insulin delivery was unable to replicate the effect of portal vein insulin delivery on liver or muscle glucose disposal whether it was the insulin dose or the glucose load (i.e., insulin's pharmacodynamic effect) that was matched. On the other hand, insulin-327 closely mirrored portal insulin's effects on glucose metabolism, including its ability to suppress HGP and to appropriately stimulate liver and muscle glucose uptake (Figure 4). Because the GIR was, if anything, lowest in Pe327, an overdose of insulin-327 cannot explain the magnitude of its effects. Finally, NHGU correlated with hepatic sinusoidal $(P<0.05)$ but not arterial insulin levels (Figure $4 \mathrm{~J})$, such that NHGU increased by $0.5 \mathrm{mg} / \mathrm{kg} / \mathrm{min}$ for each 72 -pM increase in insulin at the liver over the range of concentrations that were studied. This suggests that it was insulin's direct, not indirect, action on the liver that was responsible for the differences in NHGU.

Plasma free fatty acids (FFAs) provide a means by which insulin can indirectly regulate intrahepatic glucose metabolism because FFAs promote gluconeogenesis and limit glycolytic flux $(15,18,20)$. Arterial FFA and glycerol levels were rapidly suppressed by hyperinsulinemia in all groups due to the inhibition of lipolysis, and their net hepatic uptake rates decreased in parallel (Figure 5, A-D). Although there was a tendency for the fall in the FFA level to be delayed in Pe327, this difference was not apparent in the glycerol levels, which usually better reflect lipolysis. Previous studies have shown that when hepatic FFA uptake decreases, carbon derived from plasma glucose is diverted into the glycolytic pathway, where it can be converted into lactate and released into the circulation $(15,20)$. Indeed, an increase in net hepatic lactate output was apparent during the clamp in all groups, which resulted in a modest increase in blood lactate level during the first several hours of the clamp (Figure 5, E and F). Net hepatic carbon retention, an index of glycogen synthesis, is derived from the difference between the rate of glucose that is taken up and retained by the liver versus that which is converted into lactate and released $(27,28)$. Whereas carbon retention 
A
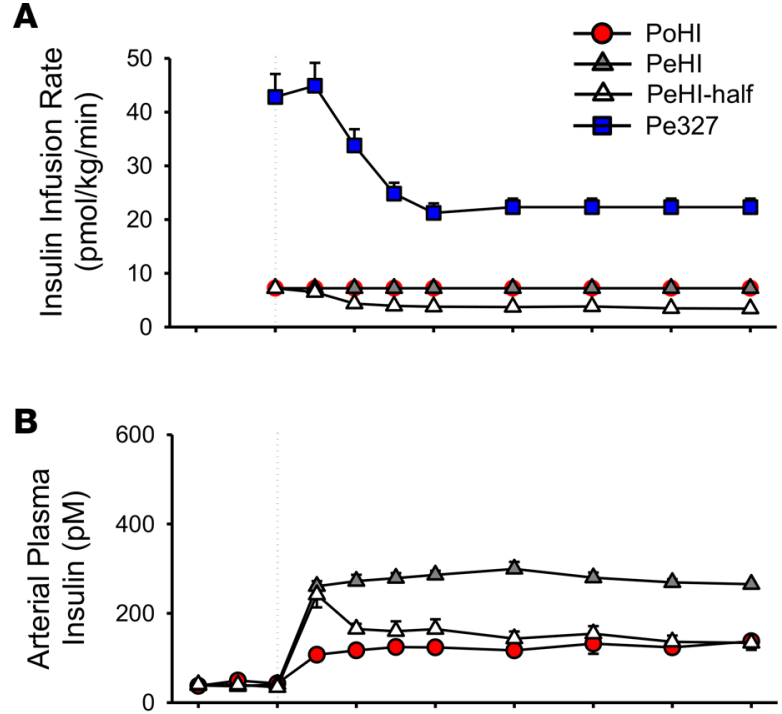

C
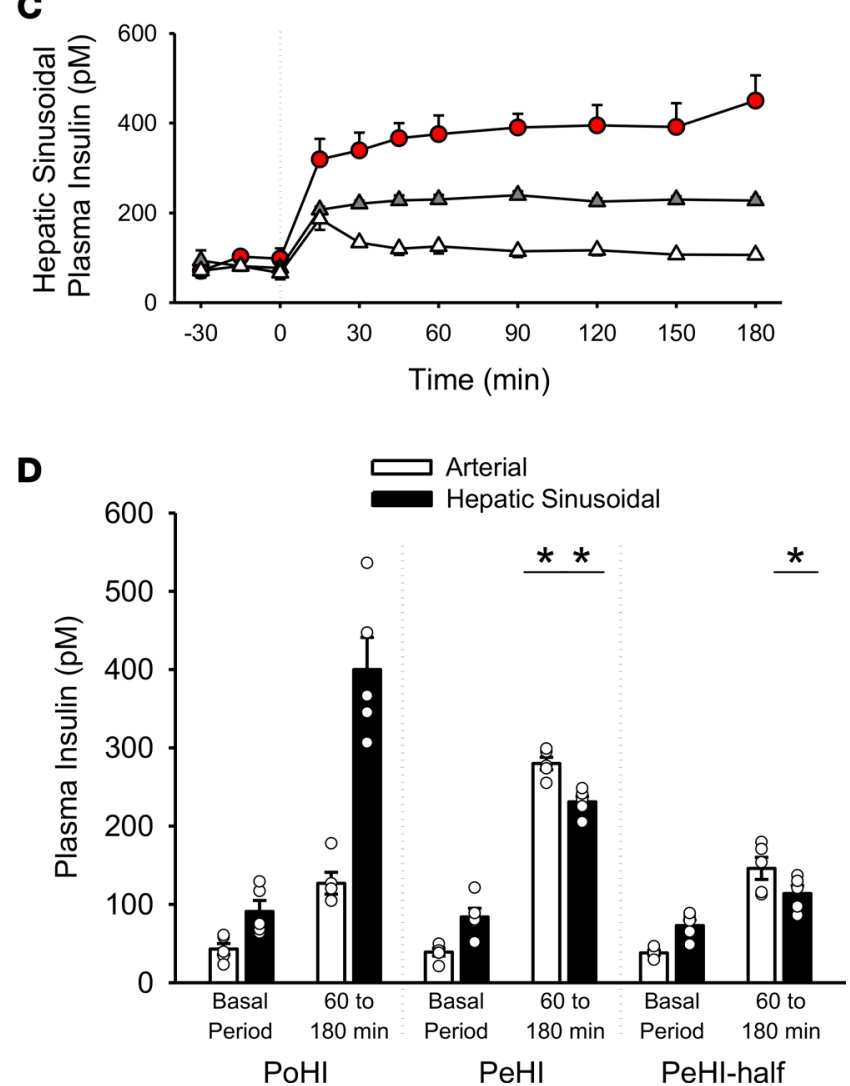

Figure 1. Insulin rates and levels. (A) Insulin infusion rates, (B) arterial plasma insulin levels, (C) hepatic sinusoidal insulin levels, and (D) average arterial and hepatic sinusoidal insulin levels during the last 2 hours of the experimental period in overnight-fasted conscious dogs in the portal vein insulin $(\mathrm{PoHI})$, peripheral vein insulin (PeHI), peripheral vein insulin half dose (PeHI-half), and peripheral vein insulin-327 (Pe327) infusion groups (mean \pm SEM; $n=5$, 5,5 , and 7, respectively; ${ }^{*} P<0.05$ vs. PoHI). Pe327 data are only shown in $\mathbf{A}$ because arterial and hepatic insulin-327 levels were high and not distinguishable between vessels (arterial, portal vein, and hepatic vein insulin-327 levels were $52,314 \pm 7,551 ; 51,100 \pm 8,146$; and $49,157 \pm 7,464$ pM; respectively, by the end of the study). 
A

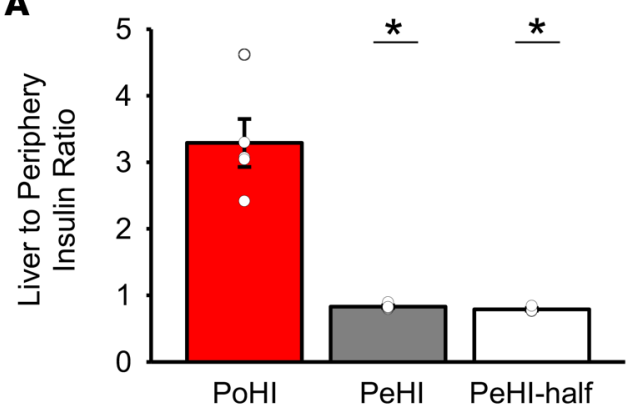

B

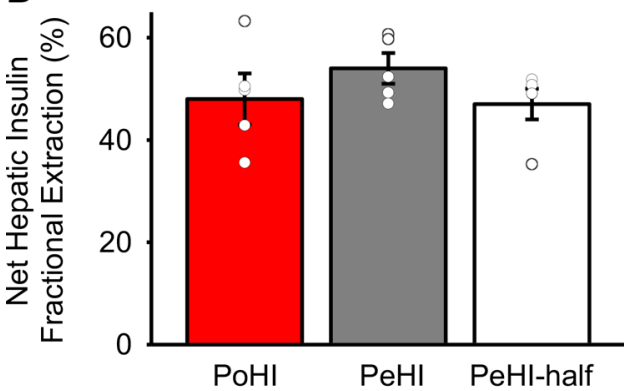

C

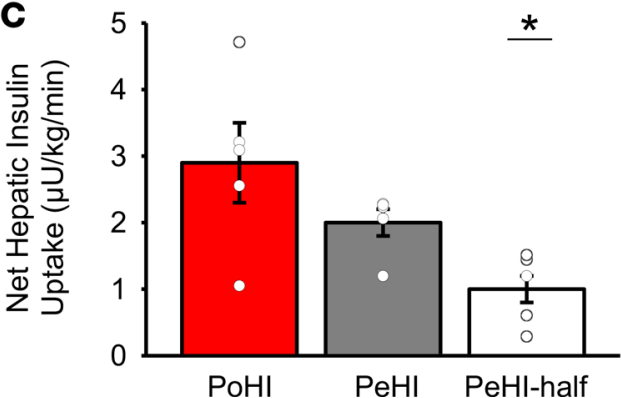

$\longrightarrow \mathrm{PoH}$

PeHI

PeHl-half
D

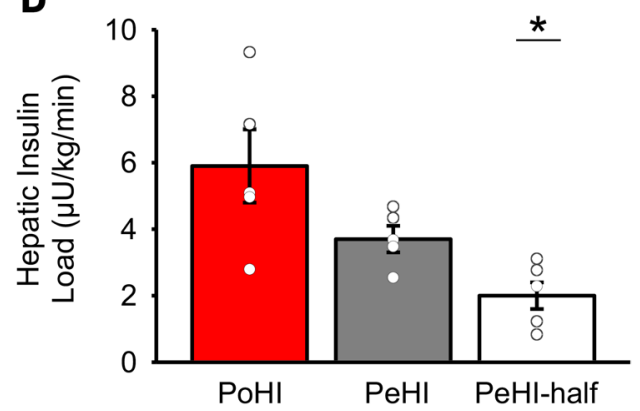

$\mathbf{E}$

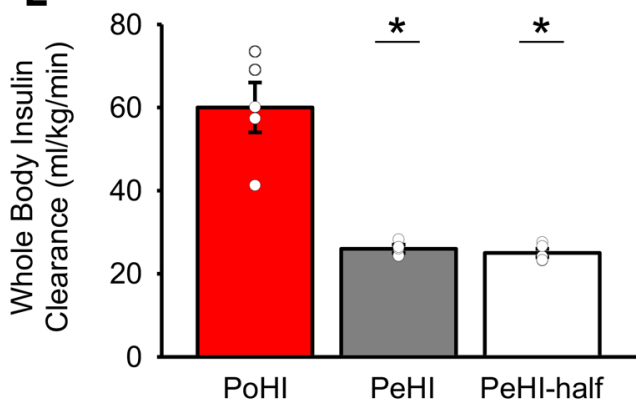

Figure 2. Insulin parameters. (A) Ratio of hepatic sinusoidal to arterial insulin level, (B) net hepatic insulin fractional extraction, net hepatic insulin uptake (C), hepatic insulin load (D), and arterial insulin clearance (E) during the last 2 hours of the experimental period in overnight-fasted conscious dogs in the portal vein insulin (PoHI), peripheral vein insulin (PeHI), and peripheral vein insulin half dose (PeHI-half) infusion groups (mean \pm SEM; $n=5$ in each; ${ }^{*}<0.05$ vs. PoHI).

by the liver was reduced with peripheral insulin delivery, it was similar in PoHI and Pe327 (Figure 5G). There were no statistically significant positive correlations between EGP and plasma FFAs, or delta EGP and delta FFAs (decrease from basal), irrespective of the route of insulin infusion. This was true regardless of which time interval was examined, including over the entire course of the experiment (Figure 5H; portal insulin: $r^{2}=0.052$ and $P=0.71$; peripheral insulin: $r^{2}=0.267$ and $P=0.13$; peripheral insulin-327 $r^{2}=0.264$ and $P=0.24$ ). Unlike in PoHI and Pe327, the slope of the EGP versus FFA regression line was positive when regular insulin was administered peripherally. These data suggest that while FFAs are not the dominant mechanism by which insulin regulates HGP under physiologic conditions, they may influence HGP during peripheral insulin delivery.

The marked effect of the route of insulin infusion on tissue glucose uptake is illustrated in Figure 6 , which demonstrates that glucose uptake was distributed evenly between muscle and the liver ( $44 \pm 9$ vs. 46 $\pm 9 \%$, respectively) during portal vein insulin infusion, but when insulin was delivered peripherally there was a shift such that muscle took up 3- to 4-fold more glucose than the liver. This occurred regardless of whether the insulin dose $(73 \% \pm 5 \%$ vs. $21 \% \pm 4 \%$, muscle vs. liver, respectively in PeHI) or total glucose load $(69 \% \pm 3 \%$ vs. $22 \% \pm 4 \%$, muscle vs. liver, respectively, in PeHI-half) were matched with the PoHI group. In contrast, insulin-327 was able to recreate the 1:1 muscle-to-liver glucose distribution ratio $(45 \% \pm$ $6 \%$ vs. $44 \% \pm 6 \%$, respectively) despite its peripheral route of delivery. 


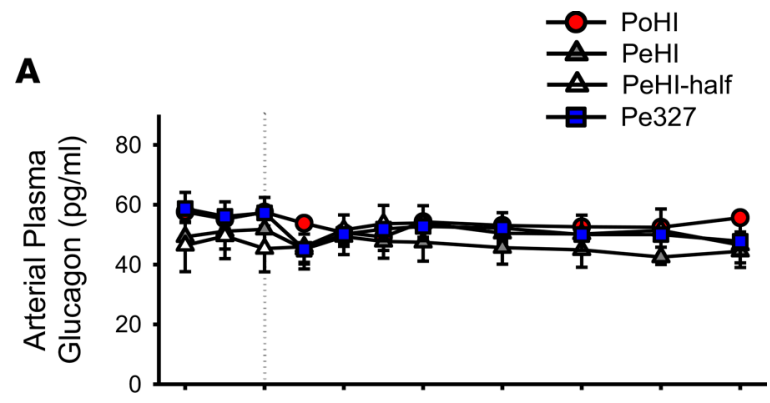

\section{B}

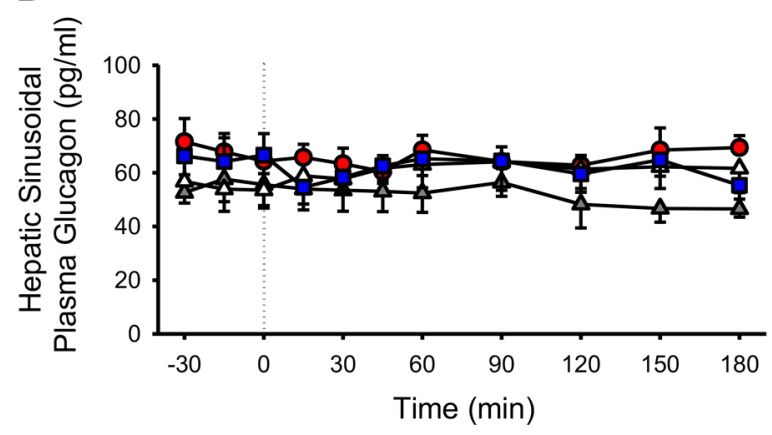

Figure 3. Glucagon levels. Arterial (A) and hepatic sinusoidal plasma (B) glucagon levels during the basal (-30 to 0 minutes) and experimental periods (0-180 minutes) in overnight-fasted conscious dogs in the portal vein insulin (PoHI), peripheral vein insulin (PeHI), peripheral vein insulin half dose (PeHI-half), and peripheral vein insulin-327 (Pe327) infusion groups (mean $\pm \mathrm{SEM} ; n=5,5,5$, and 7, respectively).

\section{Discussion}

The first aim of this study was to determine the impact of the route of insulin delivery on the regulation of hepatic glucose metabolism under postprandial glucose storage conditions. Peripheral insulin administration alters the liver-to-arterial insulin gradient, but this is only metabolically important if insulin directly regulates hepatic glucose metabolism, a concept that has been challenged $(18,19,29-32)$. On the other hand, if indirect insulin action is sufficient for its effects, as has been suggested $(18,19,29-32)$, then suppression of HGP and stimulation of HGU should correlate with arterial, not hepatic, insulin levels. This was not the case, however. Instead, the liver's response correlated with the degree to which direct insulin action was present. Even in the presence of much greater arterial insulin levels the hormone's indirect mechanisms of control were less effective than its direct effects.

This study also shows that the physiologic distribution of glucose disposal across tissues cannot be replicated by peripheral insulin infusion. A dose-independent consequence of the peripheral route of delivery was a $50 \%$ reduction in plasma insulin clearance, which overexposed muscle and other nonhepatic tissues to insulin. Because muscle has such a large capacity for glucose uptake, small alterations in arterial insulin levels can have major effects on this process, as demonstrated by the much greater rate of muscle glucose uptake that occurred with peripheral delivery. Indeed, we found that glucose uptake was equally divided between the liver and muscle under physiologic conditions, but when insulin was delivered peripherally the percentage of glucose taken up by muscle was close to 4-fold greater than that taken up by the liver, while at the same time the percentage taken up by the liver was less than half normal. Furthermore, the imbalance in glucose distribution persisted when the insulin dose was halved because liver and muscle glucose uptake decreased proportionately. Thus, normalization of the liver's response would require even greater arterial hyperinsulinemia, which in turn would further amplify the defects caused by peripheral insulin delivery (33). These data clearly demonstrate that it is impossible to normalize the glucose distribution between the liver and muscle when regular insulin is administered peripherally. This presents a significant challenge to patients treated with traditional insulin therapy, since the overdose of peripheral insulin required to compensate for the effects of its under-replacement at the liver markedly increases the risk of hypoglycemia, and the effects of dosing errors on daily glucose variability are magnified $(6,34)$. This risk is further exacerbated by the delayed onset and sustained effect of insulin on muscle glucose disposal compared with the liver, which has a rapid on-off insulin response (6). 

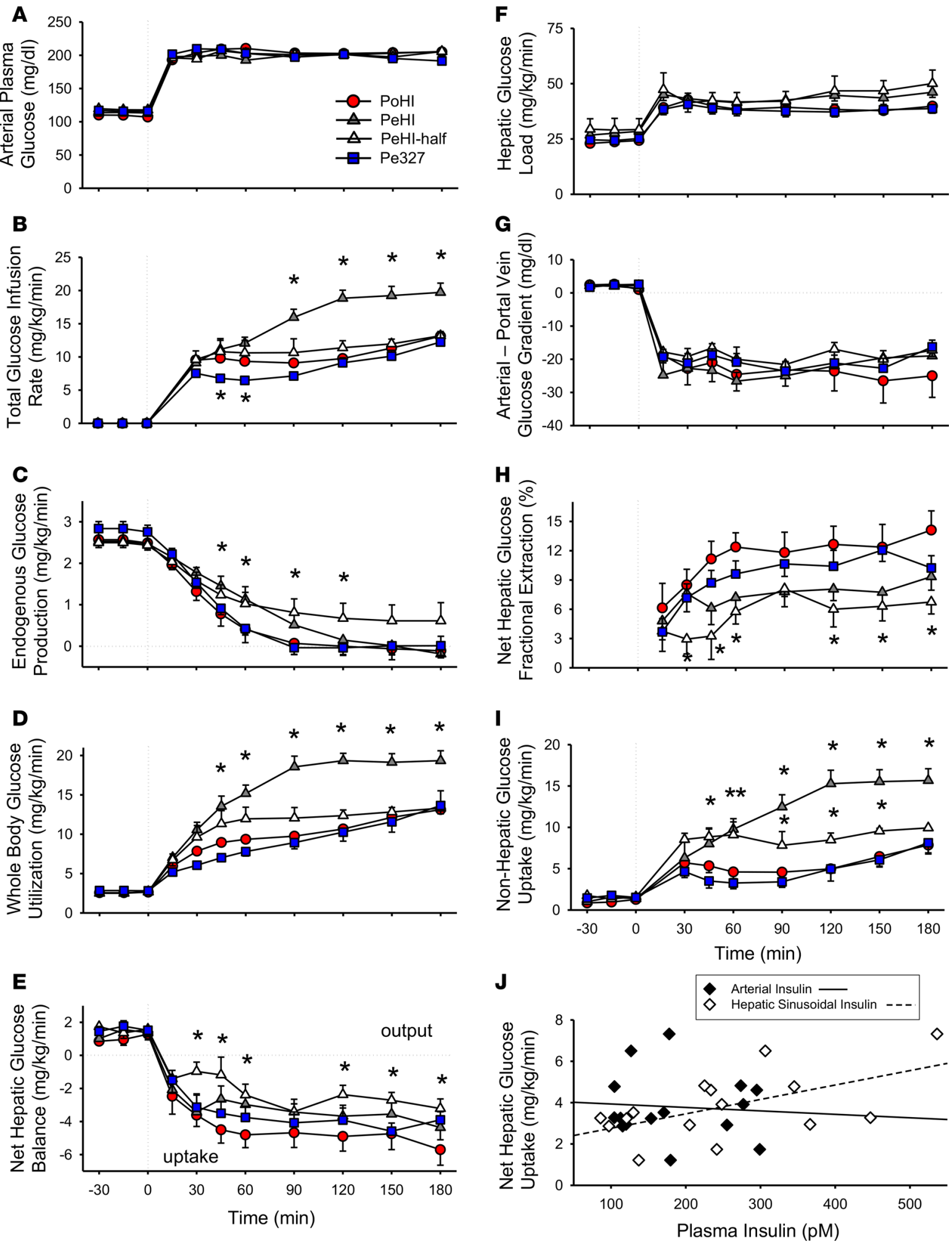

Figure 4. Glucose parameters. (A) Arterial plasma glucose, (B) total (portal + peripheral vein) glucose infusion rates, (C) endogenous glucose production, (D) whole-body glucose utilization, (E) net hepatic glucose balance, (F) hepatic glucose load, (C) arterial minus portal vein glucose gradient, (H) net hepatic glucose fractional extraction, and (I) nonhepatic glucose uptake during the basal (-30 to 0 minutes) and experimental periods ( $0-180$ minutes) in the portal vein insulin (PoHI), peripheral vein insulin (PeHI), peripheral vein insulin half dose (PeHI-half), and peripheral vein insulin-327 (Pe327) infusion groups (mean $\pm \mathrm{SEM} ; n=5,5,5$, and 7, respectively; ${ }^{*} P<0.05 \mathrm{vs}$. PoHI) in overnight-fasted conscious dogs. The vertically stacked asterisks above the 60 -minute time point in I indicate that PeHI and PeHI-half are both different $(P<0.05)$ from PoHI at 60 minutes. $(\mathrm{J})$ Linear regression of net hepatic glucose uptake versus arterial and hepatic sinusoidal insulin levels during the last 2 hours of the experimental period in the PoHI, PeHI, and PeHI-half groups (the coefficient of determination for arterial insulin was $r^{2}=0.006[P=0.78]$ and for hepatic sinusoidal insulin was $r^{2}=0.32[P=0.027]$ ). 
A
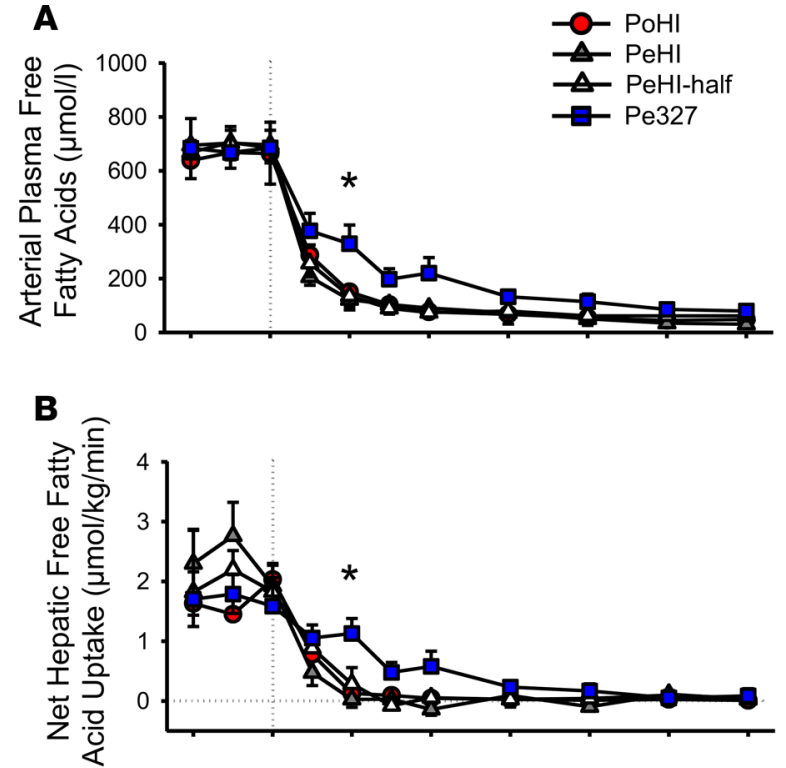

C

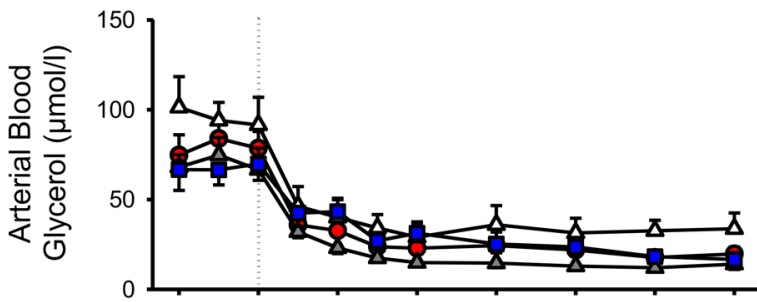

D

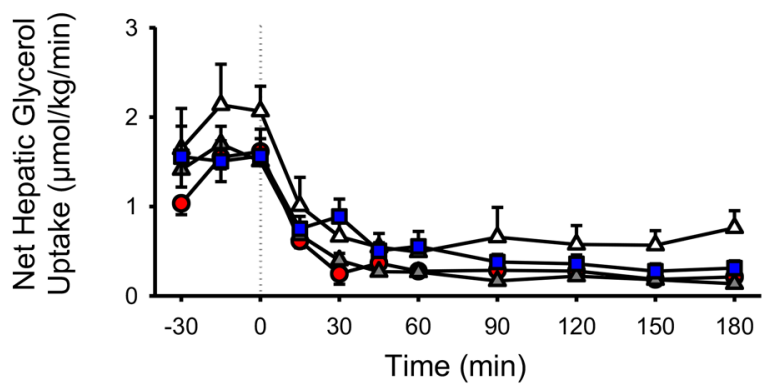

E

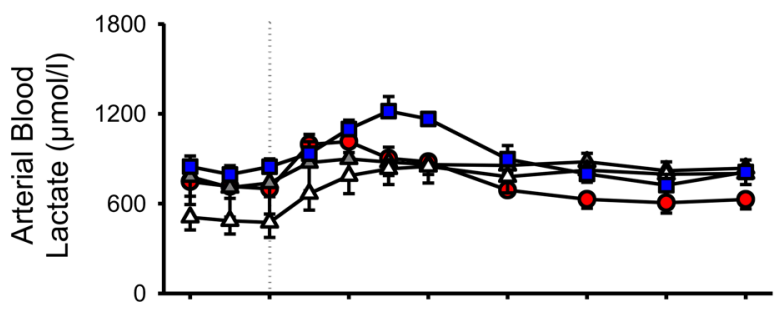

$\mathbf{F}$

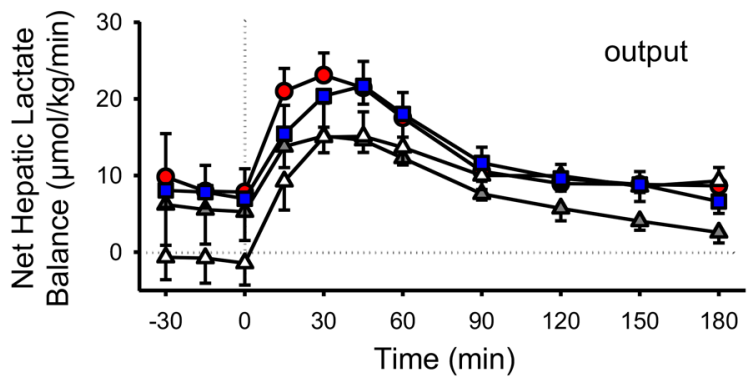

G

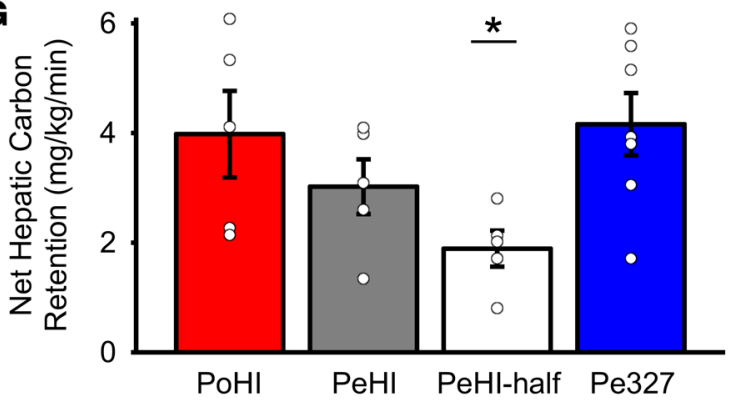

H

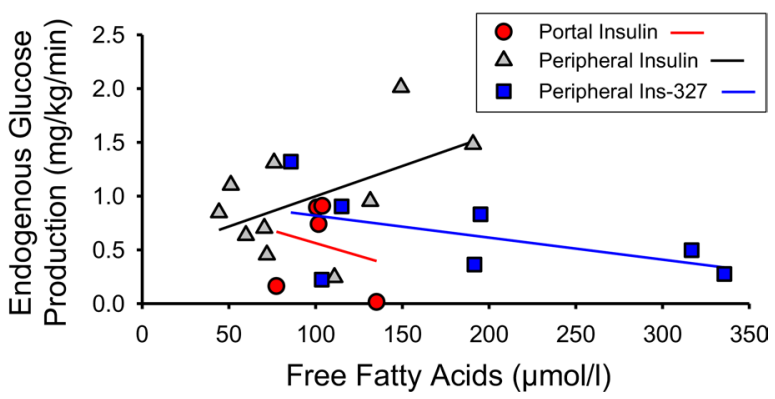

Figure 5. Metabolite parameters. (A) Arterial plasma free fatty acid levels, (B) net hepatic free fatty acid uptake, (C) arterial blood glycerol levels, (D) net hepatic glycerol uptake, (E) arterial blood lactate levels, (F) net hepatic lactate balance during the basal (-30 to 0 minutes) and experimental periods (0-180 minutes), and (G) net hepatic carbon retention during the last 2 hours of the experimental period in the portal vein insulin (PoHI), peripheral vein insulin (PeHI), peripheral vein insulin half dose (PeHI-half), and peripheral vein insulin-327 (Pe327) infusion groups (mean \pm SEM; $n=5,5,5$, and 7, respectively; ${ }^{*} P<0.05$ vs. PoHI) in overnight-fasted conscious dogs. (H) Linear regression of endogenous glucose production versus arterial plasma free fatty acids during the experimental period (the coefficients of determination were $r^{2}=0.052$ for portal human insulin $[P=0.71], r^{2}=0.267$ for peripheral human insulin $[P=0.13]$, and $r^{2}=0.264$ for peripheral insulin-327 $[P=0.24]$ ).

Excessive arterial hyperinsulinemia is associated with a myriad of defects. In addition to hypoglycemia, it is a risk factor for insulin resistance (35-37), coagulation abnormalities (38, 39), weight gain (40-42), alterations in body fat distribution and lipid metabolism $(12,43)$, atherosclerosis (44), hypertension (45), and long-term micro- and macrovascular complications, including coronary and ischemic heart disease (46-48). At the same time, hepatic insulin deficiency results in excessive glucose production (49), which is a primary contributor to hyperglycemia in individuals with type 2 diabetes (50), impaired liver glycogen storage (1), and alterations in the growth hormone - insulin-like growth hormone-1 (IGF-1) axis $(12,41,51)$. Many of these defects have been shown to improve with portal vein or intraperitoneal insulin 


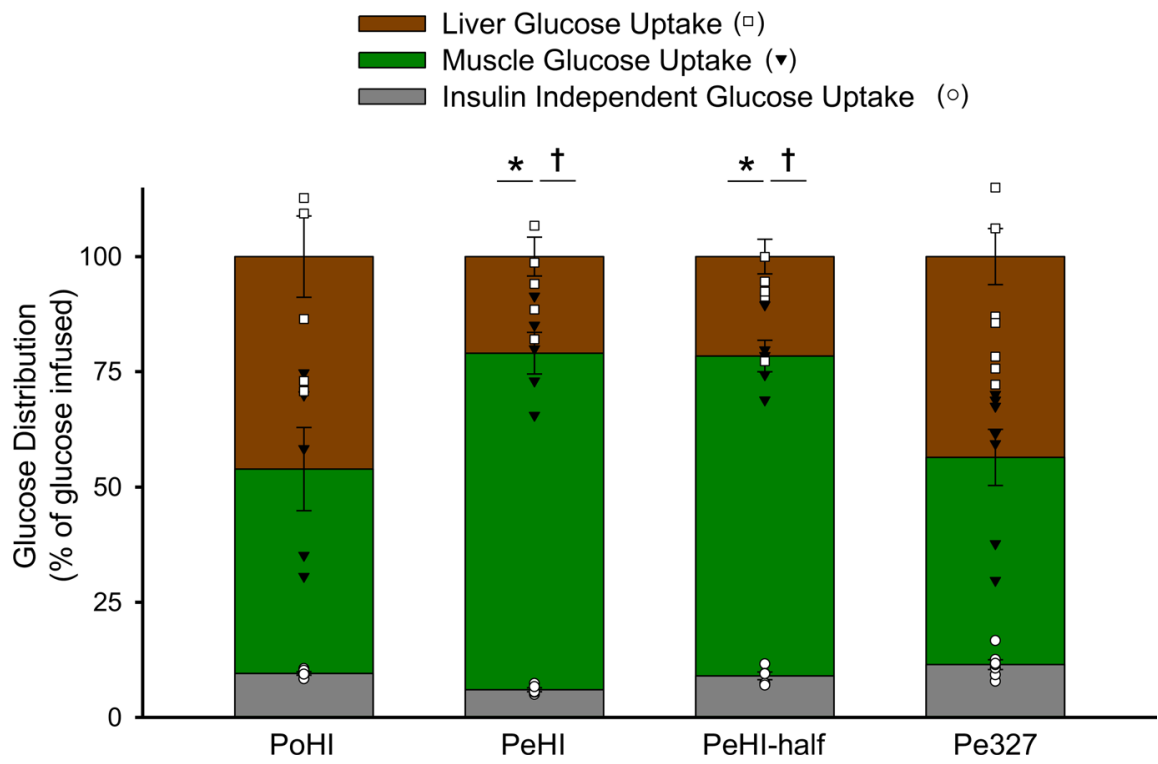

Figure 6. Glucose distribution. Liver, muscle, and insulin-insensitive tissue glucose uptake (percentage distribution) during the experimental period in overnight-fasted conscious dogs in the portal vein insulin (PoHI), peripheral vein insulin (PeHI), peripheral vein insulin half dose (PeHI-half), and peripheral vein insulin-327 (Pe327) infusion groups (mean \pm SEM; $n=5,5,5$, and 7 , respectively; ${ }^{*} P<0.05$ vs. PoHI for liver glucose uptake; ${ }^{\dagger} P<0.05$ vs. PoHI for muscle glucose uptake). The bars are stacked (sum of the 3 bars equals 100\%) with the variance and scatter plot of the data shown around the top of each bar.

treatment, including normalization of HGP and lipoprotein metabolism, correction of the levels of IGF-1 and sex-hormone-binding globulin, as well as reductions in daily glucose fluctuations, frequency of serious hypoglycemic episodes, weight gain, and hypertension in patients with type 1 or 2 diabetes $(6,12,52-57)$. Thus, the hope is that therapies that functionally restore the physiologic insulin gradient may correct some of the metabolic abnormalities associated with subcutaneous insulin delivery.

Having quantified the magnitude of the defect in liver and muscle glucose metabolism when insulin is delivered peripherally, the second aim of this study was to determine if a peripherally delivered insulin prototype, which was designed to be liver preferential, could recreate the physiologic response to insulin during hyperglycemic meal-simulated conditions. Insulin-327 is a model compound that is acylated with a 22-carbon-length fatty di-acid to promote strong but reversible binding to plasma albumin. Hepato-preferentiality is conferred because insulin-327's ability to cross the tight endothelial capillary barrier at muscle is limited, whereas the fenestrated sinusoids of the liver are relatively open to large plasma constituents (58). In a previous euglycemic study we found that insulin-327 had hepato-preferential effects on glucose turnover when infused at a rate that mimicked the effect of close to basal fasting levels of endogenous insulin (7). In the present study, insulin-327 almost perfectly replicated the effects of an elevation in portal vein insulin on both HGP and HGU during feeding conditions. In addition, the fate of glucose taken up by the liver was normalized, which is important because HGU is abnormal in individuals with diabetes $(4,5)$ and restoration of the liver glycogen pool would help correct the low hepatic glycogen content that occurs $(1,59)$. In turn, this might minimize hypoglycemic risk (60). Furthermore, the physiologic 50/50 distribution of glucose uptake by liver and muscle was completely corrected by insulin-327, providing proof of principle that a peripherally delivered hepato-preferential insulin analog can replicate the physiologic metabolic response to glucose ingestion.

One concern with regard to hepato-preferential insulin analogs is the potential for insulin-stimulated activation of hepatic lipogenesis without concomitant suppression of adipose tissue lipolysis. Under such conditions it is possible that unrestrained hepatic FFA uptake could lead to hepatic lipid accumulation (61). Indeed, the development of a promising hepato-preferential insulin analog (LY2605541) $(8,62)$ was recently ended prior to its entry into phase III trials after elevated alanine transaminases and in some cases increased hepatic fat content were observed in treated individuals (63). Although the insulin-327 analog used in our study is a model compound not intended for clinical use, the differential effects of hepato-preferential insulin analogs on liver and fat should be considered in their development. Unlike LY2605541 (8), insulin-327 caused 
rapid suppression of arterial glycerol and FFA levels, although there was a tendency for the fall in FFAs and therefore decrease in hepatic FFA uptake to be briefly delayed in the present study. Thus, while there are many potential benefits of hepato-preferential insulin therapy, it appears possible that an analog can be too hepato-selective. In our view, the ideal candidate is one that is hepato-preferential to the degree to which it recreates the effects of intraportal insulin on liver, muscle, and fat when given peripherally.

It has been previously concluded that insulin's indirect effects are most important to the control of HGP $(18,19,29-32)$, whereas in the present study suppression of HGP did not correlate with fat or brain insulin exposure (Figure 4J). This discrepancy can most likely be explained by the differences in arterial to hepatic insulin levels during peripheral versus portal vein clamps. The peripheral route will always favor the indirect effects of insulin because the 3:1 ratio of insulin at the liver versus artery is lost during a peripheral clamp (endogenous insulin secretion is suppressed by exogenous insulin even without somatostatin infusion) $(15,22,64)$. As a result, when arterial insulin levels are clamped at 3-fold basal by infusion of the hormone into a peripheral vein, hepatic insulin levels actually remain at baseline (7). Thus, in this frequently used, so-called, "hyperinsulinemic" clamp paradigm (18, 21, 30-32, 65-67) suppression of HGP is the result of insulin's indirect, not direct, action. The present study supports previous findings that have shown that when insulin's direct and indirect effects oppose each other it is the hormone's direct effect that is dominant (49) and that insulin's direct effect is sufficient to fully inhibit HGP, regardless of whether or not peripheral insulin action increases $(15,16,23)$.

Although in the present study liver glucose metabolism correlated with hepatic, not arterial insulin levels, it is clear that insulin can control HGP through both direct and indirect mechanisms $(16,66)$. We cannot conclude from our data that insulin's indirect effects were not important to the liver's normal response for several reasons. First, hepatic insulin levels must be matched between groups to fully discriminate between the effects of differences in arterial insulin levels, but they were not. Second, FFA levels were close to maximally suppressed regardless of the route of insulin delivery; therefore, to a large extent this indirect mechanism of insulin action was fully engaged in all groups. Indeed, a fall in FFAs stimulates glycolytic flux, which in turn increases the release of lactate from the liver $(15,20)$, and this occurred to a similar extent in all groups. In particular the FFA levels were so low and tightly clustered in the PoHI group that there was little room to examine the effect of a range of FFA levels on liver glucose metabolism (Figure $5 \mathrm{H}$ ). FFAs per se were previously shown to reduce HGU under basal insulin conditions (68), suggesting that FFA levels may be important under certain circumstances. Therefore, submaximal doses of insulin could be used to test the impact of differences in insulin-mediated suppression of lipolysis on HGU. It should be noted, however, that the modest, 3-fold rise in arterial insulin obtained in the present study was sufficient to markedly suppress lipolysis in the PoHI group, whereas a 15-fold increase in insulin can occur following a meal (59); thus, insulin levels were well within the physiologic range. Alternatively, a fat clamp (20) could be used to prevent a fall in FFAs during feeding conditions. Of note, there was a lag in the suppression of FFAs in the Pe327 group but this was not accompanied by a corresponding lag in the suppression of HGP (Figure $5 \mathrm{H}$ ), further supporting the notion that insulin's direct effects dominate the control of this process under physiological conditions $(15,23,49,69)$. On the other hand, although not statistically significant, when human insulin was delivered peripherally glucose production rates were positively associated with FFA levels (Figure 5H). It is not surprising that FFAs would have a greater potential influence on liver glucose flux when hepatic insulin levels are reduced. Third, glucagon opposes HGU (70) and glucagon secretion is suppressed by insulin $(71,72)$, but this mechanism was not in play in the present study because glucagon was clamped at basal levels. Finally, we have shown that brain insulin action can activate pathways in the liver that could promote $\operatorname{HGU}(23,69,73)$. Further studies will be required to dissect and quantify the importance of these mechanisms to the control of HGU.

In summary, poor control of hepatic glucose metabolism is a cause of hyperglycemia in individuals with diabetes. Previous studies have concluded that indirect insulin action, mediated through the peripheral effects of arterial insulin, is the dominant mechanism by which insulin regulates the liver. If true, targeting insulin to the liver would not be expected to provide a therapeutic advantage. The present study demonstrates that peripherally delivered insulin generates a very different vascular insulin profile compared with endogenously secreted insulin. This alters insulin clearance, changes the exposure of insulin-sensitive tissues to the hormone, and as a result has definite metabolic consequences. Peripherally delivered insulin clearly cannot replicate the physiologic regulation of hepatic glucose metabolism or the distribution of postprandial glucose uptake across tissues. This suggests that insulin therapy that 
preferentially targets the liver (by route of delivery or analog modification) may provide superior control of liver and whole-body glucose metabolism and thus might have a therapeutic advantage over subcutaneous injection of regular insulin.

\section{Methods}

Animals and surgical procedures. Studies were carried out on 22 conscious 18-hour-fasted dogs of either sex (20$23 \mathrm{~kg}$ ). The surgical and animal care facilities met the standards published by the American Association for the Accreditation of Laboratory Animal Care, and diet and housing were provided as previously described (74).

Approximately 16 days before study, the animals underwent surgery for placement of sampling catheters in a femoral artery and the hepatic portal and hepatic veins, and infusion catheters in the splenic and jejunal veins, which drain into the portal vein (74). Ultrasonic flow probes (Transonic Systems) were placed around the hepatic portal vein and the hepatic artery, as described previously (74). The proximal ends of the catheters and flow probes were tucked into subcutaneous pockets at the end of the surgical procedure. All dogs were determined to be healthy prior to experimentation, as indicated by (a) leukocyte count $<18,000 / \mathrm{mm}^{3}$, (b) hematocrit $>35 \%$, and (c) good appetite (consuming at least $75 \%$ of the daily ration). On the morning of the experiment the catheters and flow probe leads were exteriorized from their subcutaneous pockets under local anesthesia. Intravenous (i.v.) catheters were also inserted into peripheral leg veins for infusion of glucose and hormones as necessary.

Experimental design. Each experiment consisted of a 90-minute tracer equilibration period ( -120 to $-30 \mathrm{~min}$ utes), a 30-minute basal sample collection period ( -30 to 0 minutes), and a 3-hour experimental period (0-180 minutes). At -120 minutes, a primed continuous i.v. infusion of $\left[3-{ }^{3} \mathrm{H}\right]$-glucose $(42 \mu \mathrm{Ci}$ prime and $0.35 \mu \mathrm{Ci} / \mathrm{min}$ continuous rate; PerkinElmer) was started in order to calculate rates of glucose production and uptake. At 0 minutes, somatostatin $(0.8 \mu \mathrm{g} / \mathrm{kg} / \mathrm{min}$; Bachem) was infused to suppress pancreatic insulin and glucagon secretion and glucagon was replaced intraportally at a basal rate $(0.5 \mathrm{ng} / \mathrm{kg} / \mathrm{min})$. To simulate gut glucose absorption, glucose was infused into the hepatic portal vein at a constant rate in all groups ( $4 \mathrm{mg} / \mathrm{kg} / \mathrm{min})$, and also into a peripheral vein as needed to maintain arterial plasma glucose levels at $200 \mathrm{mg} / \mathrm{dl}$ (approximately 2-fold basal). Also at 0 minutes, regular human insulin was infused into either the portal vein (PoHI; $7.2 \mathrm{pmol} / \mathrm{kg} / \mathrm{min}$; $n=5$ ) or a peripheral vein at the same rate (PeHI; $7.2 \mathrm{pmol} / \mathrm{kg} / \mathrm{min} ; n=5)$. In a third group, insulin was infused into a peripheral vein at rates that were titrated (PeHI-half; approximately $3.6 \mathrm{pmol} / \mathrm{kg} / \mathrm{min}$ at steady state; $n=5$ ) throughout the experimental period so that the total GIR in PeHI-half would match with the GIR occurring in PoHI. In a fourth group, insulin-327 (Novo Nordisk A/S) was infused into a peripheral vein at a titrated rate (Pe327; approximately $21 \mathrm{pmol} / \mathrm{kg} / \mathrm{min}$ at steady state; $n=7$ ) as required to match the GIR in Pe327 with that in PoHI. We chose to study the regulation of glucose metabolism under steady-state conditions in order to obtain more accurate assessments of insulin action and glucose flux rates over a longer period.

Plasma glucose was measured using a GM9 glucose analyzer (Analox Instruments Ltd) and plasma $\left[3-{ }^{3} \mathrm{H}\right]$ glucose and nonesterified FFA and blood glycerol concentrations were determined as previously described (74). Plasma insulin (PI-12K, MilliporeSigma) and glucagon (GL-32K, MilliporeSigma) were measured by radioimmunoassay. Proinsulin cross-reactivity in the insulin assay could lead to a small overestimation ( $4 \%$ ) of endogenous insulin levels in the fasted state (75), but this amount would be negligible during the somatostatin clamp with elevated exogenous insulin $(76,77)$.

Insulin-327. Insulin-327 (A22Lys[ $N^{\varepsilon}(\mathrm{S})$-(22,42-dicarboxy-10,19,24-trioxo-3,6,12,15-tetraoxa-9,18,23-triazadotetracontan-1-oyl)], B29Arg, desB30 human insulin) is an acylated model compound designed to test the pharmacodynamic effects of this modification on hepatic versus nonhepatic glucose metabolism. Fatty acid acylation of the compound promotes binding to albumin, which leads to a protracted mode of action and provides its hepato-preferentiality $(7,78)$. Evaluation of an analog depends on equating its dose to a comparator. This was done by matching the pharmacodynamic effects (i.e., GIR) of peripherally delivered insulin-327 with portal and peripheral delivery of regular insulin.

Plasma insulin-327 levels were analyzed using a luminescence oxygen channeling immunoassay (LOCI) as described previously (79). During the assay, a concentration-dependent bead-analyte-immune complex is created, resulting in light output, which is measured on an EnVision plate reader (PerkinElmer). Coupling of antibodies to beads, biotinylation of antibodies, and LOCI assay procedure were performed as previously described (80). Calibrators and quality control samples were produced in the same matrix as the study samples. Assay precision was assessed and the coefficient of variation was shown to be lower than $20 \%$ for all the tested samples. For the quantification of insulin-327 in dog plasma the assay 
used the monoclonal antibody NN454-1F31 (raised against insulin Degludec), conjugated acceptor beads with biotinylated S1 monoclonal antibody (raised against ordinary human insulin), and generic streptavidin-coated donor beads. LLOQ for insulin-327 in dog plasma was 70 pM. Cross-reactivity to endogenous dog insulin was shown to be lower than $0.1 \%$.

Calculations and data analysis. Net hepatic glucose balance (NHGB) was calculated as NHGB = $\mathrm{LOAD}_{\text {out }}-\mathrm{LOAD}_{\text {in }}$. The $\operatorname{LOAD}_{\text {in }}=\left([\mathrm{A}] \times \mathrm{F}_{\mathrm{A}}\right)+\left([\mathrm{P}] \times \mathrm{F}_{\mathrm{P}}\right)$ and $\operatorname{LOAD}_{\text {out }}=\left([\mathrm{H}] \times \mathrm{F}_{\mathrm{H}}\right)$, where $\mathrm{A}, \mathrm{P}$, and $\mathrm{H}$ refer to the arterial, portal vein, and hepatic vein glucose concentrations, respectively, and $\mathrm{F}_{\mathrm{A}}, \mathrm{F}_{\mathrm{P}}$, and $\mathrm{F}_{\mathrm{H}}$ refer to the arterial, portal vein, and hepatic vein (total liver) blood flow. Nonhepatic glucose uptake equaled the GIR minus NHGB, where the rate was corrected for changes in the size of the glucose pool, using a pool fraction of $0.65 \mathrm{ml} / \mathrm{kg}(81)$ and assuming that the volume of distribution for glucose equaled the volume of the extracellular fluid, or approximately $22 \%$ of the dog's weight (82). For all glucose balance calculations, glucose concentrations were converted from plasma to blood values using correction factors (ratio of the blood to the plasma concentration) previously established in our laboratory $(83,84)$. Glucose turnover, used to estimate EGP (predominantly HGP) and whole-body glucose uptake, was measured using $3{ }^{3} \mathrm{H}$ glucose infusion based on the circulatory model of Mari et al. (85).

Insulin-independent glucose uptake was estimated to be $67 \%$ (approximately $1 \mathrm{mg} / \mathrm{kg} / \mathrm{min}$ ) of net hepatic glucose output in the basal state and it was assumed to remain stable throughout the clamp period (86). The distribution of the infused glucose was based on percentage contributions of each component (NHGU, muscle glucose uptake, and insulin-independent glucose uptake) to the total GIR. Although nonhepatic insulin-dependent glucose uptake represents glucose uptake by fat and muscle, the latter is by far dominant, especially in lean animals; thus, it is referred to as such $(50,87)$.

The approximate plasma insulin level entering the liver sinusoids was calculated using the formula $[\mathrm{A}] \times \% \mathrm{~F}_{\mathrm{A}}+[\mathrm{P}] \times \% \mathrm{~F}_{\mathrm{P}}$, where $[\mathrm{A}]$ and $[\mathrm{P}]$ are arterial and portal vein hormone concentrations, respectively, and $\% \mathrm{~F}_{\mathrm{A}}$ and $\% \mathrm{~F}_{\mathrm{P}}$ are the respective percentage contributions of arterial and portal flow to total hepatic blood flow. Whole-body (arterial) insulin clearance was determined by dividing the insulin infusion rate by its arterial concentration. Net hepatic insulin fractional extraction was calculated by dividing net hepatic insulin uptake by hepatic insulin $\mathrm{LOAD}_{\text {in }}$

Statistics. Statistical comparisons were carried out with SigmaStat (Systat Software) using ANOVA for repeated measures with Student-Newman-Keuls post hoc analysis. Statistical significance was accepted when $P<0.05$. Data are expressed as mean \pm SEM.

Study approval. The protocol was approved by the Vanderbilt University Institutional Animal Care and Use Committee.

\section{Author contributions}

DSE and ADC designed the studies and wrote the manuscript. DSE, MS, and BF conducted the experiments and acquired and analyzed data. BF and PEW performed the surgeries. PM, TK, CLB, CF, and EN provided insulin-327 and contributed to study design. All authors reviewed the manuscript.

\section{Acknowledgments}

This work was funded by Novo Nordisk. Hormone analysis was performed by Vanderbilt's Hormone Assay and Analytical Services Core, and surgical and experimental expertise was provided by Vanderbilt's Large Animal Core, both of which are supported by the Vanderbilt Diabetes Research and Training Center grant DK-20593.

Address correspondence to: Dale S. Edgerton, 710 RRB 2200 Pierce Avenue, Nashville, Tennessee 37232-0615, USA. Phone: 615.343.3193; Email: dale.edgerton@vanderbilt.edu.

1. Hwang $\mathrm{JH}$, et al. Impaired net hepatic glycogen synthesis in insulin-dependent diabetic subjects during mixed meal ingestion. A ${ }^{13} \mathrm{C}$ nuclear magnetic resonance spectroscopy study. J Clin Invest. 1995;95(2):783-787.

2. Ferrannini E, Wahren J, Felig P, DeFronzo RA. The role of fractional glucose extraction in the regulation of splanchnic glucose metabolism in normal and diabetic man. Metab Clin Exp. 1980;29(1):28-35.

3. Capaldo B, et al. Splanchnic and leg substrate exchange after ingestion of a natural mixed meal in humans. Diabetes. 1999;48(5):958-966.

4. Basu R, Basu A, Johnson CM, Schwenk WF, Rizza RA. Insulin dose-response curves for stimulation of splanchnic glucose uptake and suppression of endogenous glucose production differ in nondiabetic humans and are abnormal in people with type 2 diabetes. Diabetes. 2004;53(8):2042-2050. 
5. Ludvik B, et al. Evidence for decreased splanchnic glucose uptake after oral glucose administration in non-insulin-dependent diabetes mellitus. J Clin Invest. 1997;100(9):2354-2361.

6. Arbit E. The physiological rationale for oral insulin administration. Diabetes Technol Ther. 2004;6(4):510-517.

7. Edgerton DS, et al. Changes in glucose and fat metabolism in response to the administration of a hepato-preferential insulin analog. Diabetes. 2014;63(11):3946-3954.

8. Moore MC, et al. Novel PEGylated basal insulin LY2605541 has a preferential hepatic effect on glucose metabolism. Diabetes. 2014;63(2):494-504.

9. Arbit E, Kidron M. Oral insulin: the rationale for this approach and current developments. J Diabetes Sci Technol. 2009;3(3):562-567.

10. Wong CY, Martinez J, Dass CR. Oral delivery of insulin for treatment of diabetes: status quo, challenges and opportunities. J Pharm Pharmacol. 2016;68(9):1093-1108.

11. Bally L, Thabit H, Hovorka R. Finding the right route for insulin delivery - an overview of implantable pump therapy. Expert Opin Drug Deliv. 2017;14(9):1103-1111.

12. van Dijk PR, Logtenberg SJ, Gans RO, Bilo HJ, Kleefstra N. Intraperitoneal insulin infusion: treatment option for type 1 diabetes resulting in beneficial endocrine effects beyond glycaemia. Clin Endocrinol (Oxf). 2014;81(4):488-497.

13. Radziuk J, Pye S, Seigler DE, Skyler JS, Offord R, Davies G. Splanchnic and systemic absorption of intraperitoneal insulin using a new double-tracer method. Am J Physiol. 1994;266(5 Pt 1):E750-E759.

14. Cherrington AD, Edgerton D, Sindelar DK. The direct and indirect effects of insulin on hepatic glucose production in vivo. Dia betologia. 1998;41(9):987-996.

15. Edgerton DS, et al. Insulin's direct hepatic effect explains the inhibition of glucose production caused by insulin secretion. JCI Insight. 2017;2(6):e91863.

16. Sindelar DK, Balcom JH, Chu CA, Neal DW, Cherrington AD. A comparison of the effects of selective increases in peripheral or portal insulin on hepatic glucose production in the conscious dog. Diabetes. 1996;45(11):1594-1604.

17. Lewis GF, Vranic M, Harley P, Giacca A. Fatty acids mediate the acute extrahepatic effects of insulin on hepatic glucose production in humans. Diabetes. 1997;46(7):1111-1119.

18. Perry RJ, et al. Hepatic acetyl CoA links adipose tissue inflammation to hepatic insulin resistance and type 2 diabetes. Cell. 2015;160(4):745-758

19. Rebrin K, Steil GM, Mittelman SD, Bergman RN. Causal linkage between insulin suppression of lipolysis and suppression of liver glucose output in dogs. J Clin Invest. 1996;98(3):741-749.

20. Sindelar DK, Chu CA, Rohlie M, Neal DW, Swift LL, Cherrington AD. The role of fatty acids in mediating the effects of peripheral insulin on hepatic glucose production in the conscious dog. Diabetes. 1997;46(2):187-196.

21. Titchenell PM, et al. Direct hepatocyte insulin signaling is required for lipogenesis but is dispensable for the suppression of glucose production. Cell Metab. 2016;23(6):1154-1166.

22. Farmer TD, et al. Comparison of the physiological relevance of systemic vs. portal insulin delivery to evaluate whole body glucose flux during an insulin clamp. Am J Physiol Endocrinol Metab. 2015;308(3):E206-E222.

23. Ramnanan CJ, Edgerton DS, Cherrington AD. Evidence against a physiologic role for acute changes in CNS insulin action in the rapid regulation of hepatic glucose production. Cell Metab. 2012;15(5):656-664.

24. Moore MC, Coate KC, Winnick JJ, An Z, Cherrington AD. Regulation of hepatic glucose uptake and storage in vivo. Adv Nutr. 2012;3(3):286-294.

25. Rossetti L, Giaccari A, Barzilai N, Howard K, Sebel G, Hu M. Mechanism by which hyperglycemia inhibits hepatic glucose production in conscious rats. Implications for the pathophysiology of fasting hyperglycemia in diabetes. J Clin Invest. 1993;92(3):1126-1134.

26. Dube S, Errazuriz-Cruzat I, Basu A, Basu R. The forgotten role of glucose effectiveness in the regulation of glucose tolerance. Curr Diab Rep. 2015;15(6):605.

27. Moore MC, et al. Sources of carbon for hepatic glycogen synthesis in the conscious dog. J Clin Invest. 1991;88(2):578-587.

28. Satake S, et al. Direct and indirect effects of insulin on glucose uptake and storage by the liver. Diabetes. 2002;51(6):1663-1671.

29. Bergman RN. Non-esterified fatty acids and the liver: why is insulin secreted into the portal vein? Diabetologia. 2000;43(7):946-952.

30. Okamoto H, Obici S, Accili D, Rossetti L. Restoration of liver insulin signaling in Insr knockout mice fails to normalize hepatic insulin action. J Clin Invest. 2005;115(5):1314-1322.

31. Buettner C, et al. Severe impairment in liver insulin signaling fails to alter hepatic insulin action in conscious mice. J Clin Invest. 2005;115(5):1306-1313.

32. Obici S, Zhang BB, Karkanias G, Rossetti L. Hypothalamic insulin signaling is required for inhibition of glucose production. Nat Med. 2002;8(12):1376-1382.

33. Evans ML. Too much or too little? The double jeopardy of subcutaneous insulin therapy in diabetes. Diabetes. 2015;64(10):3353-3354.

34. Gregory JM, et al. Insulin delivery into the peripheral circulation: a key contributor to hypoglycemia in type 1 diabetes. Diabetes. 2015;64(10):3439-3451.

35. Cao W, Liu HY, Hong T, Liu Z. Excess exposure to insulin may be the primary cause of insulin resistance. Am J Physiol Endocrinol Metab. 2010;298(2):E372.

36. Hall JE, Brands MW, Zappe DH, Alonso Galicia M. Insulin resistance, hyperinsulinemia, and hypertension: causes, consequences, or merely correlations? Proc Soc Exp Biol Med. 1995;208(4):317-329.

37. Shanik MH, Xu Y, Skrha J, Dankner R, Zick Y, Roth J. Insulin resistance and hyperinsulinemia: is hyperinsulinemia the cart or the horse? Diabetes Care. 2008;31 Supp1 2:S262-S268.

38. McFarlane SI, Banerji M, Sowers JR. Insulin resistance and cardiovascular disease. J Clin Endocrinol Metab. 2001;86(2):713-718

39. Sowers JR, Sowers PS, Peuler JD. Role of insulin resistance and hyperinsulinemia in development of hypertension and atherosclerosis. J Lab Clin Med. 1994;123(5):647-652.

40. Larger E. Weight gain and insulin treatment. Diabetes Metab. 2005;31(4 Pt 2):4S51-4S56.

41. Russell-Jones D, Khan R. Insulin-associated weight gain in diabetes--causes, effects and coping strategies. Diabetes Obes Metab. 2007;9(6):799-812. 
42. Sallé A, Ryan M, Guilloteau G, Bouhanick B, Berrut G, Ritz P. 'Glucose control-related' and 'non-glucose control-related' effects of insulin on weight gain in newly insulin-treated type 2 diabetic patients. Br J Nutr. 2005;94(6):931-937.

43. Stout RW. Insulin and atheroma. 20-yr perspective. Diabetes Care. 1990;13(6):631-654.

44. Stout RW. Hyperinsulinemia and atherosclerosis. Diabetes. 1996;45 Suppl 3:S45-S46.

45. Tseng CH. Exogenous insulin use and hypertension in adult patients with type 2 diabetes mellitus. Arch Intern Med. 2006;166(11):1184-1189.

46. Conway B, Costacou T, Orchard T. Is glycaemia or insulin dose the stronger risk factor for coronary artery disease in type 1 diabetes? Diab Vasc Dis Res. 2009;6(4):223-230.

47. Hirai FE, Moss SE, Klein BE, Klein R. Relationship of glycemic control, exogenous insulin, and C-peptide levels to ischemic heart disease mortality over a 16-year period in people with older-onset diabetes: the Wisconsin Epidemiologic Study of Diabetic Retinopathy (WESDR). Diabetes Care. 2008;31(3):493-497.

48. Kronmal RA, Barzilay J, Tracy RP, Savage PJ, Orchard TJ, Burke GL. The relationship of fasting serum radioimmune insulin levels to incident coronary heart disease in an insulin-treated diabetic cohort. J Clin Endocrinol Metab. 2004;89(6):2852-2858.

49. Edgerton DS, et al. Insulin's direct effects on the liver dominate the control of hepatic glucose production. J Clin Invest. 2006;116(2):521-527.

50. Mitrou $\mathrm{P}$, et al. Rates of glucose uptake in adipose tissue and muscle in vivo after a mixed meal in women with morbid obesity. J Clin Endocrinol Metab. 2009;94(8):2958-2961.

51. Hanaire-Broutin $\mathrm{H}$, et al. Effect of intraperitoneal insulin delivery on growth hormone binding protein, insulin-like growth factor (IGF)-I, and IGF-binding protein-3 in IDDM. Diabetologia. 1996;39(12):1498-1504.

52. Duckworth WC, et al. The Veterans Affairs Implantable Insulin Pump Study: effect on cardiovascular risk factors. Diabetes Care. 1998;21(10):1596-1602.

53. Liebl A, et al. A reduction in severe hypoglycaemia in type 1 diabetes in a randomized crossover study of continuous intraperitoneal compared with subcutaneous insulin infusion. Diabetes Obes Metab. 2009;11(11):1001-1008.

54. Robert JJ, Chauvet D, Darmaun D, Leblanc H. Hepatic glucose production during intraperitoneal and intravenous closed-loop insulin regulation of blood glucose in type 1 (insulin-dependent) diabetic patients. Diabetologia. 1993;36(11):1185-1190.

55. Saudek CD, et al. Implantable insulin pump vs multiple-dose insulin for non-insulin-dependent diabetes mellitus: a randomized clinical trial. Department of Veterans Affairs Implantable Insulin Pump Study Group. JAMA. 1996;276(16):1322-1327.

56. Selam JL, Raccah D, Jean-Didier N, Lozano JL, Waxman K, Charles MA. Randomized comparison of metabolic control achieved by intraperitoneal insulin infusion with implantable pumps versus intensive subcutaneous insulin therapy in type I diabetic patients. Diabetes Care. 1992;15(1):53-58.

57. Shishko PI, Kovalev PA, Goncharov VG, Zajarny IU. Comparison of peripheral and portal (via the umbilical vein) routes of insulin infusion in IDDM patients. Diabetes. 1992;41(9):1042-1049.

58. Herring R, Jones RH, Russell-Jones DL. Hepatoselectivity and the evolution of insulin. Diabetes Obes Metab. 2014;16(1):1-8

59. Krssak M, et al. Alterations in postprandial hepatic glycogen metabolism in type 2 diabetes. Diabetes. 2004;53(12):3048-3056.

60. Winnick JJ, et al. Hepatic glycogen can regulate hypoglycemic counterregulation via a liver-brain axis. J Clin Invest. 2016;126(6):2236-2248

61. Riddle MC. Lessons from Peglispro: IMAGINE how to improve drug development and affordability. Diabetes Care. 2016;39(4):499-501

62. Henry RR, et al. Basal insulin peglispro demonstrates preferential hepatic versus peripheral action relative to insulin glargine in healthy subjects. Diabetes Care. 2014;37(9):2609-2615.

63. Hirose T. Development of new basal insulin peglispro (LY2605541) ends in a disappointing result. Diabetol Int. 2016;7(1):16-17.

64. Liljenquist JE, Horwitz DL, Jennings AS, Chiasson JL, Keller U, Rubenstein AH. Inhibition of insulin secretion by exogenous insulin in normal man as demonstrated by C-peptide assay. Diabetes. 1978;27(5):563-570.

65. Lu M, et al. Insulin regulates liver metabolism in vivo in the absence of hepatic Akt and Foxo1. Nat Med. 2012;18(3):388-395.

66. Titchenell PM, Chu Q, Monks BR, Birnbaum MJ. Hepatic insulin signalling is dispensable for suppression of glucose output by insulin in vivo. Nat Commun. 2015;6:7078.

67. Pocai A, et al. Hypothalamic K(ATP) channels control hepatic glucose production. Nature. 2005;434(7036):1026-1031.

68. Moore MC, et al. Nonesterified fatty acids and hepatic glucose metabolism in the conscious dog. Diabetes. 2004;53(1):32-40.

69. Ramnanan CJ, et al. Interaction between the central and peripheral effects of insulin in controlling hepatic glucose metabolism in the conscious dog. Diabetes. 2013;62(1):74-84.

70. Holste LC, Connolly CC, Moore MC, Neal DW, Cherrington AD. Physiological changes in circulating glucagon alter hepatic glucose disposition during portal glucose delivery. Am J Physiol. 1997;273(3 Pt 1):E488-E496.

71. Cooperberg BA, Cryer PE. Insulin reciprocally regulates glucagon secretion in humans. Diabetes. 2010;59(11):2936-2940.

72. Meier JJ, Kjems LL, Veldhuis JD, Lefèbvre P, Butler PC. Postprandial suppression of glucagon secretion depends on intact pulsatile insulin secretion: further evidence for the intraislet insulin hypothesis. Diabetes. 2006;55(4):1051-1056.

73. Ramnanan CJ, et al. Brain insulin action augments hepatic glycogen synthesis without suppressing glucose production or gluconeogenesis in dogs. J Clin Invest. 2011;121(9):3713-3723.

74. Edgerton DS, et al. Small increases in insulin inhibit hepatic glucose production solely caused by an effect on glycogen metabolism. Diabetes. 2001;50(8):1872-1882.

75. Wang PW, Abbasi F, Carantoni M, Chen YD, Azhar S, Reaven GM. Insulin resistance does not change the ratio of proinsulin to insulin in normal volunteers. J Clin Endocrinol Metab. 1997;82(10):3221-3224.

76. Lavelle-Jones M, Scott MH, Kolterman O, Rubenstein AH, Olefsky JM, Moossa AR. Selective suppression of hepatic glucose output by human proinsulin in the dog. Am J Physiol. 1987;252(2 Pt 1):E230-E236.

77. Røder ME, Kahn SE. Suppression of beta-cell secretion by somatostatin does not fully reverse the disproportionate proinsulinemia of type 2 diabetes. Diabetes. 2004;53 Suppl 3:S22-S25.

78. Havelund $\mathrm{S}$, et al. The mechanism of protraction of insulin detemir, a long-acting, acylated analog of human insulin. Pharm Res. 2004;21(8):1498-1504.

79. Poulsen F, Jensen KB. A luminescent oxygen channeling immunoassay for the determination of insulin in human plasma. J Biomol 
Screen. 2007;12(2):240-247.

80. Petersen SB, Lovmand JM, Honoré L, Jeppesen CB, Pridal L, Skyggebjerg O. Comparison of a luminescent oxygen channeling immunoassay and an ELISA for detecting insulin aspart in human serum. J Pharm Biomed Anal. 2010;51(1):217-224.

81. Cowan JS, Hetenyi G. Glucoregulatory responses in normal and diabetic dogs recorded by a new tracer method. Metab Clin Exp. 1971;20(4):360-372.

82. Steele R. Influences of glucose loading and of injected insulin on hepatic glucose output. Ann N Y Acad Sci. 1959;82:420-430.

83. Hsieh PS, et al. The head arterial glucose level is not the reference site for generation of the portal signal in conscious dogs. Am J Physiol. 1999;277(4):E678-E684.

84. Pagliassotti MJ, Holste LC, Moore MC, Neal DW, Cherrington AD. Comparison of the time courses of insulin and the portal signal on hepatic glucose and glycogen metabolism in the conscious dog. J Clin Invest. 1996;97(1):81-91.

85. Mari A, Stojanovska L, Proietto J, Thorburn AW. A circulatory model for calculating non-steady-state glucose fluxes. Validation and comparison with compartmental models. Comput Methods Programs Biomed. 2003;71(3):269-281.

86. Cherrington AD. Control of glucose production in vivo by insulin and glucagon. In: Jefferson LSC, A.D. ed. Handbook of Physiology. New York: Oxford University Press; 2001:759-785

87. DeFronzo RA, Jacot E, Jequier E, Maeder E, Wahren J, Felber JP. The effect of insulin on the disposal of intravenous glucose Results from indirect calorimetry and hepatic and femoral venous catheterization. Diabetes. 1981;30(12):1000-1007 